
\title{
3 Research Soure \\ Indications for the potential of Cry1Ab1 for inhibiting aphid development and virus transmission
}

Liang Jin

Huaqiao University

Binwu Zhang

Huaqiao University

Xiaodi Zhao

Huaqiao University

Luis Carlos Ramos Aguila

Fujian Agriculture and Forestry University

Yi Lin ( $\nabla$ lyhxm@hqu.edu.cn)

Huaqiao University

\section{Research Article}

Keywords: Aphid development, Bacillus thuringiensis, Cry1Ab1, Cry-binding proteins, Mechanism model, Virus transmission

Posted Date: April 7th, 2022

DOI: https://doi.org/10.21203/rs.3.rs-1236673/v2

License: (c) (1) This work is licensed under a Creative Commons Attribution 4.0 International License. Read Full License 


\section{Abstract}

Cry1A-type toxins are insecticidal proteins from Bacillus thuringiensis that are widely used to control Lepidoptera pests, and they are believed to be useless for the control of Hemiptera pests. In this paper, the purified Cry1Ab1 toxic core rarely killed peach aphids (Myzus persicae), as its Lethal Concentration 50 $\left(\mathrm{LC}_{50}\right)$ was up to $1308.6 \mu \mathrm{g} / \mathrm{ml}$, as measured using the membrane-encapsulation method. We then identified the proteins that bind to the Cry1Ab1 toxic core in M. persicae using pull-down assays and liquid chromatography-tandem mass spectrometry (LC-MS/MS), and then analyzed the associated functions of these proteins using the STRING database. GPN-loop GTPase 2, beta-actin, ATP synthase subunit alpha and an unknown and annotated protein, which are mainly involved in cell phagocytosis, RNA polymerase, cellular oxidative phosphorylation and other related functions, were the proteins that bound to the Cry1Ab1 toxic core. Indications from docking showed that Cry1Ab1 toxic core, ATP synthase subunit alpha and beta-actin or Cry1Ab1 toxic core, ATP synthase subunit alpha and GPN-loop GTPase 2 being a complex to exert effects. Based on the identification of Cry1Ab1-binding proteins from M.persicae, we presented here the molecular clues that Cry1A exert a negative effect on aphid growth and development, and we also proposed that Cry protein had the ability to disturb virus transmission by aphid. The two indications will result in new insights for aphid-effective Cry evaluation and improvement.

\section{Introduction}

In recent years, the extensive use of Bacillus thuringiensis (Bt) pesticides in China has increased. The total proportion of Bt biopesticides in the microbial pesticide market in China has exceeded 95\% (Park. et al. 2014). As one type of gram-positive bacteria (Stenfors Arnesen et al. 2008), Bt exhibits a wide global distribution. During the formation of spores, Bt produces parasporal crystals whose main component is insecticidal crystal proteins, such as the Cry protein. The key function of the Cry protein is to interact with specific receptors on insect midgut brush border membrane vesicles (BBMVs), such as cadherin (CAD), aminopeptidase N (APN), alkaline phosphatase (ALP) and ABC transporter (Pigott and Ellar. 2007; Park. et al. 2014). As shown in our recent study, Cry-binding proteins are present in the midgut juice of insects and might interfere with the insecticidal process of Cry toxins. Trypsin-like serine proteases and Dorsal (a member of NF-KB transcription factors in arthropods that regulates the expression of the downstream target genes in the Toll signaling pathway (Tanji and Ip. 2005) were reported to be Cry1 Ab1-binding proteins in the midgut juice of Plutella xylostella, and Peroxidase-C was a Cry $1 \mathrm{Ab}$-binding protein in Spodoptera exigua (Lu et al. 2017). Zhao et al found that Cry41-realted interacted with Cathepsin B and enhanced its activity, causing acceleration of apoptosis of aphid cells (Zhao et al. 2020). Additionally, galectin-14 was reported to compete with Cry11Aa for binding to BBMVs and ALP1 in Aedes aegypti to prevent effective binding of the toxin to receptors (Zhang et al. 2018). Hence, the mechanisms for Cry toxins against insects are believed to be much more complicated than before.

Aphididae (aphid) is one type of sucking insects of the order Hemiptera. Approximately 4,700 aphid species have been identified, of which approximately 450 damage crops (Favert. et al. 2007). Aphids suck plant sap using sharp mouthparts, and chlorophyllase and pectinase in their saliva affect plant growth 
and development (Yusuf. and Collins. 1998). Moreover, aphids, such as peach aphid, are important viral vectors (Farooq et al. 2010) and have been shown to spread more than 100 plant viruses (Scholthof et al. 2011). Therefore, the harm and loss caused by viral diseases mediated by aphid-induced transmission are far greater than the damage caused by direct sucking (Halbert. et al. 2004).

Although chemical insecticides are still mainly used to control aphids, pathogenic microorganisms, such as viruses, fungi, bacteria, and parasitic wasps, have been considered substitutes to control aphids, due to effects on the environment and human health and the resistance of aphids to various pesticides (Ban et al. 2008; Shan and Feng. 2010). Researchers planned to use Cry protein for aphid control. Recent studies reported that Cry41-related toxin showed moderate toxicity against Myzus persicae with its $\mathrm{LC}_{50}$ was $32.7 \mu \mathrm{g} / \mathrm{mL}$ (Palma et al. 2014), and that Cry1Cb2 toxin exhibited high toxicity against Myzus persicae with $\mathrm{LC}_{50}$ of $6.58 \mathrm{ng} / \mu \mathrm{L}$ (Torres-Quintero et al. 2022), however, most Cry protein displayed very low level of toxicity to sucking insects (Hemiptera) (Chougule and Bonning. 2012).

In this paper, we performed the assay using a typical Cry protein Cry1Ab1 to determine its effects on the most destructive aphid M. persicae, and we identified the proteins bound by Cry $1 \mathrm{Ab} 1$ toxic core using pull-down and LC-MS/MS assays. Molecular dockings between Cry1Ab1 toxic core and its binding proteins were performed to find out the way they interact. Furthermore, Cry-binding proteins were submitted to the STRING database to analyze their functions and associated mechanisms. We then proposed a model for the inhibitory effect of Cry1Ab1 on the aphid development and reproduction, and we speculated that the Cry $1 \mathrm{~A}$ protein had the ability to disrupt aphid-mediated virus transmission. The results will result in new insights for aphid-effective Cry1 A evaluation and improvement.

\section{Materials And Methods}

\section{Experimental materials}

M. persicae were reared on Brassica chinensis L., which was cultured in an artificial climate chamber (JINGHONG, Shanghai, China) with temperature of $20 \pm 2^{\circ} \mathrm{C}$, relative humidity of $70-80 \%$, and photoperiod of $L: D=16: 8$. The Escherichia colistrain expressing the Cry1Ab1 toxic core was preserved in our lab. CNBr-activated Sepharose ${ }^{\mathrm{TM}}$ 4B was purchased (GE Healthcare, Fairfield, CT, U.S.A.).

\section{Preparation of the Cry1Ab1 toxic core}

The expression and purification of the Cry $1 \mathrm{Ab} 1$ toxic core were performed using the methods described by Lu (Lu et al. 2017).

\section{Bioassay of the effects of the Cry1Ab1 toxic core on M. persicae (membrane capsule method)}

The stretched $8 * 8 \mathrm{~cm}^{2}$ parafilm was attached to one end of a cylinder (diameter of $4 \mathrm{~cm}$, height of $3 \mathrm{~cm}$, and wall thickness of $2 \mathrm{~mm}$ ) with a circular cross section. Five milliliters of culture medium (containing 
$10,100,150$, or $250 \mu \mathrm{g} / \mathrm{ml}$ Cry $1 \mathrm{Ab} 1$ ) were added to the membrane, which was subsequently covered with a layer of parafilm to form a capsule.

After M. persicae were cultured for several generations in the incubator, 30 healthy 4 th instars M. persicae were placed in the lower layer of each capsule, each treatment was repeated 3 times. A $6 * 6 \mathrm{~cm}$ parafilm square with 20 to 30 vent holes (transparent and breathable film) was used to seal the other end of the cylindrical bracket. The bioassay device was placed at a temperature of $18-20^{\circ} \mathrm{C}$, humidity of $80 \%$, and photoperiod of $L: D=16: 8$ for 7 days. The aphids were gently touched with a brush at the same time every day to assess death (non-responders were considered dead), and the data were recorded for the statistical analysis.

\section{Pull down experiment}

The M. persicae homogenate was extracted from 200 healthy 3th instars M. persicae using a tissue grinder. The pull down experiment was performed using the method described by Lu (Lu et al. 2017), and the results of the separation were analyzed using polyacrylamide gel electrophoresis (SDS-PAGE), followed by silver staining.

\section{LC-MS/MS analysis}

The silver-stained SDS-PAGE gel was carefully observed, and the bands that appeared in all treatment groups, but not in the control group, were excised and sent to Beijing Huada Protein Research and Development Center (HPRC) for LC-MS/MS analysis. HPRC performed a search of the LC-MS/MS data against the uni-Aphidoidea 33385 database (52,503 sequences and 17,662,111 residues) using the MASCOT search engine (Matrix Science, London, UK). The results were submitted to the BLAST program of the National Center of Biotechnology Information (NCBI), and the accession numbers and related information of the interacting proteins were subsequently obtained.

\section{Molecular docking and binding sites analysis}

Three-dimensional (3D) structures of Cry1Ab1 toxic core and Cry-binding proteins were predicted by PHYRE2. GRAMM-X Protein-Protein Docking Web Server v.1.2.0 was used to predict the molecular docking of Cry $1 \mathrm{Ab} 1$ toxic core and Cry-binding proteins, and then the docking results was analyzed and showed in the Discovery Studio 2.5 (Kang et al. 2017; Zhang et al. 2018). The functional domain of Crybinding proteins was acquired from the UniProt database.

\section{Protein-protein interaction analysis}

The STRING database integrates protein-protein interaction data from numerous predicted and known organisms, including direct (physical) interactions with specific biological functions and indirect (functional) interactions (Cun and Frohlich. 2013). Therefore, the sequences of those proteins binding to the Cry1Ab1 toxic core were submitted to the STRING server for the analysis of functional protein interaction networks. 


\section{Results}

\section{The Cry1Ab1 toxic core rarely kills the aphid $M$. persicae}

The assay against $M$. persicae using the membrane capsule method was performed with four different concentrations of the purified Cry1Ab1 toxic core (Fig. 1). The corrected mortality rates of the Cry1Ab1 toxic core at concentrations of $10,100,150$, and $250 \mu \mathrm{g} / \mathrm{ml}$ were $0.11,0.13,0.15$ and 0.17 , respectively. The calculated virulence regression equation was $y=-0.0003 x+0.8926$, and the correlation coefficient was $\mathrm{p}=0.9857>0.95$. The $\mathrm{LC}_{50}$ was calculated to be $1308.6 \mu \mathrm{g} / \mathrm{ml}>>500 \mu \mathrm{g} / \mathrm{ml}$, indicating that the Cry1 Ab1 toxic core rarely kills M. persicae. This result is consistent with the finding reported by Porcar, who showed that the activity of the trypsin-activated Cry1Ab toward Acyrthosiphon pisum using artificial diet bioassays was very low, with only a $25 \%$ mortality rate observed at a high concentration $(500 \mu \mathrm{g} / \mathrm{ml})$ (Porcar et al. 2009).

\section{GPN-loop GTPase 2, beta-actin, ATP synthase subunit alpha and an unknown and annotated protein in M. persicae were pulled down as proteins that bound to the Cry1Ab1 toxic core}

The proteins that bound to the Cry $1 \mathrm{Ab} 1$ toxic core were isolated using the pull down method, separated on SDS-PAGE gels, and subjected to silver staining (Fig. 2). The treatment group displayed an obvious band at approximately $55 \mathrm{kDa}$ compared with the control. The LC-MS/MS results are shown in Table 1. The BLAST analysis revealed that the proteins that bound to the Cry1Ab1 toxic core were beta-actin ( $\beta$ actin), ATP synthase subunit alpha, GPN-loop GTPase2 (Gpn2) of the GTPase protein family and an unannotated protein. Some of these proteins or their homologues have been identified as Cry-binding proteins in many insects. V-ATPase subunit $A$ and actin were identified as CrylAc-binding proteins in the midgut of Heliothis virescens (Krishnamoorthy et al. 2007); V-ATPase subunit B and actin were identified as Cry1 Ac-binding proteins in Helicoverpa armigera (Chen et al. 2010). Hence, ATPase and actin are two common Cry-binding proteins in insects. The fact that the proteins we identified are common Cry-binding proteins suggested that the protocol used in this paper was suitable for isolating and identifying Crybinding proteins. Intriguingly, Gpn2, a member of the GPN family of GTPases, was first described in this paper as a Cry-binding protein. GTPase bind and hydrolyze GTP to produce GDP and inorganic phosphate, and they have various functions, including protein synthesis, cell differentiation, energy metabolism and signal transduction (Bourne. et al. 1990; Sprang. 1997; Feng et al. 2014).

Table 1 LC-MS/MS identification for Cry1Ab1 toxic core binding proteins in M. Persicae 


\begin{tabular}{|llll|}
\hline Sample & Accession number & Sore & Protein description \\
\hline 1 & tr|T1UMS9|T1UMS9_APHGO & 82 & $\begin{array}{l}\text { Beta-actin } \\
\text { OS = Aphis gossypii }\end{array}$ \\
\hline 2 & tr|J9K1R5|J9K1R5_ACYPI & 31 & GPN-loop GTPase 2 OS = Acyrthosiphon pisum \\
\hline 4 & tr|J9M0Y0|J9M0Y0_ACYPI & 29 & $\begin{array}{l}\text { Uncharacterized protein OS = Acyrthosiphon } \\
\text { pisum }\end{array}$ \\
\hline tr|Q5XUA1|Q5XUA1_TOXCI & 28 & $\begin{array}{l}\text { ATP synthase subunit alpha OS = Toxoptera } \\
\text { citricida }\end{array}$ \\
\hline
\end{tabular}

\section{Cry1 Ab1 toxic core bind to the functional domain of Cry-binding proteins and form different complexes}

3D-Structure of Cry1Ab1 toxic core and its binding proteins including ATP synthase subunit alpha, $\beta$-actin and Gpn2 were predicted (Fig. 3). Molecular docking was performed (Fig. 4-A, B, C), and the interacting residues were showed in yellow.

For ATP synthase subunit alpha, there are three functional domains, 67-133, 190-413 and 420-545, respectively. Its interface with Cry $1 \mathrm{Ab}$ is involved in 55E, 57-63ILGAPPK, 67-68EE, 98S, 100L, 118-119GN, 121-122KL, 128V, 130K, 142-143ED, 150D, 154-165NTIDGKGPLTSK, 251R and 278-280SDA, which located in the first and second functional domain (Fig. 4-D). There is only one functional domain in $\beta$ actin, 3-376. Its interface with Cry1 Ab is involved in 40R, 60Q, 63-70RGILTLKY, 73-74EH, 158-160DGV, 180185DLAGRD, 188-189DY, 191-192MK, 196E, 207R, 225-226EQ, 228-230MAT, 232-233AA, 264Q, 266273SFLGMESC and 277E (Fig. 4-E). Similarly, Gpn2 has one functional domain, 8-257. Its interface with Cry1 Ab is involved in 145-148SDPG, 147-148YI, 154L, 178-181AVKH, 184-185KL, 188-192NLDFY, 194195DV, 201L, 205L and 242R (Fig. 4-F).

The interaction residues on Cry1Ab1 toxic core with ATP synthase subunit alpha were widely distributed

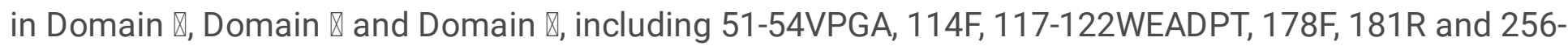

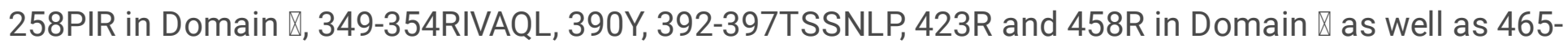
466II, 469S, 514-521NITAPLSQ, 578-580SNG and 608-610EVT in Domain $\otimes$ (Fig. 5-A). The interaction

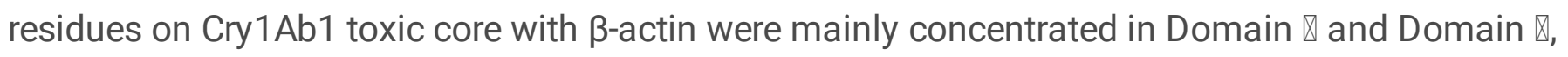

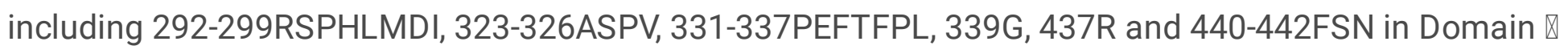
and 479-488STNLGSGTSV, 501-507RRTSPGQ, 587S and 589-594HVFNSG in Domain $\otimes$ (Fig. 5-B). Interestingly, the interaction residues on Cry1Ab1 toxic core with Gpn2 were highly similar with that of $\beta$ actin, including 289-298GSIRSPHLMD, 324-326SPV, 329-339SGPEFTFPLYG, 435-437MFR and 440-

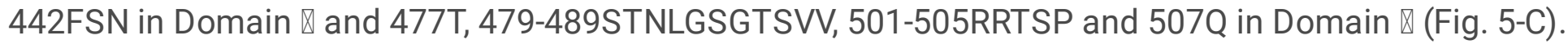
The interface of ATP synthase subunit alpha on Cry1Ab1 toxic core does not overlap with that of $\beta$-actin or Gpn2, and ATP synthase subunit alpha bind on one side and $\beta$-actin or Gpn2 on another side, indicating that ATP synthase subunit alpha, $\beta$-actin and Cry1Ab1 toxic core form a complex while ATP synthase subunit alpha, Gpn2 and Cry1Ab1 toxic core form another complex. Then, the complex 3D 
models were constructed and displayed (Fig. 5-D and Fig. 5-E). ATP synthase subunit alpha (yellow) and $\beta$-actin (purple) bind to Cry1Ab1 toxic core (green) on different sides (Fig. 5-D). Similarly, ATP synthase subunit alpha (yellow) and Gpn2 (blue) bind to Cry1Ab1 toxic core (green) on different sides (Fig. 5-E).

\section{The proteins that bound to Cry1 Ab1 toxic core are involved in the growth and development of aphids}

The sequences of the proteins that bound to the Cry1Ab1 toxic core were submitted to the STRING server for analyses of the related pathways. Their functional distributions are shown in Fig. 6. These proteins are mainly involved in cell phagocytosis, RNA polymerase, cellular oxidative phosphorylation and other related functions. These processes or pathways play an important role in the growth and development of organisms. Phagocytosis is a highly conserved innate immune mechanism that not only eliminates foreign microbial pathogens but also digests apoptotic or necrotic cell debris from many cells. When phagocytosis occurs, foreign substances are recognized by cells, bound to the cell surface, and engulfed into the cells by phagosomes (Stuart and Ezekowitz. 2008; Nizet. 2010). RNA polymerase is involved in gene transcription and is very important for the normal expression of genes and organization of development (Zeng et al. 2018). Oxidative phosphorylation refers to the process of releasing energy as a result of the oxidation of organic matter in the organism and drives the synthesis of ATP, which is necessary for sustaining the synthesis of chemicals that maintain metabolism and cell structure, and for the transport of the ions and molecules that maintain the intracellular environment (Wilson. 2017).

The proteins bound by Cry1Ab1 toxic core are mainly involved in the phagosome, RNA polymerase and oxidative phosphorylation.

\section{Discussion}

Although the Cry toxin protein possesses specific insecticidal activity against a variety of agricultural and forestry pests, aphids are not sensitive to it (Faria et al. 2007). Therefore, the study aiming to uncover the reasons for this insensitivity will give us valuable implications for evaluating and improving its activity against the aphid. We confirmed that Cry1Ab1 toxic core exerted very low ability for killing M. persicae, then we identified the proteins that bind to the Cry1Ab1 toxic core in M. persicae, and analyzed the docking interface between Cry1Ab1 and its three binding proteins, ATP synthase subunit alpha, beta-actin and Gpn2, performed STRING database searching to find their related pathways, all those suggesting that they formed protein complex to disturb the growth and development of the aphid.

ATPase, which is known as the "pH meter" of the cell, regulates $\mathrm{pH}$ to modulate enzymatic activity, thereby affecting the metabolic rate of the cell. V-ATPase on the membrane also functions as a receptor to regulate the $\mathrm{pH}$-mediated endocytosis and exocytosis in cells (Forgac. 1998; Toei et al. 2010). According to Whyard et al (Whyard et al. 2009), the consumption of the V-ATPase dsRNA caused the death of Drosophila melanogaster, Tribolium castaneum, A. pisum and Manduca sexta. ATP synthase subunit alpha consists of a soluble domain at the $\mathrm{N}$-terminus in the cytoplasm and a transmembrane region containing 9 a-helices at the $\mathrm{C}$-terminus. Several amino acid residues located at the $\mathrm{C}$-terminus 
participate in proton transport and the formation of $\mathrm{H}^{+}$channels (Peri and Nüsslein-Volhard. 2008). According to the chemical permeation theory, V-ATPase transports protons, and ATP is synthesized using the $\mathrm{H}^{+}$potential during the process of oxidative phosphorylation. Based on the analysis described above, ATP synthase subunit alpha is presumed to participate in the proton transport required for ATP synthesis mediated by oxidative phosphorylation. Meanwhile, docking interface analysis indicated that Cry1Ab1 toxic core bound with the functional domain of ATP synthase subunit alpha, Therefore, the interaction between Cry $1 \mathrm{Ab} 1$ toxic core and ATP synthase subunit alpha might interfere with oxidative phosphorylation, affecting the normal energy supply in the cells and thereby disrupting the metabolic reactions in the cells and even inhibiting the growth and development of aphids.

Actin has been identified as one of the Cry-binding proteins in Mythimna separate (Feng et al. 2016), $H$. virescens (Krishnamoorthy et al. 2007), H. armigera (Chen et al. 2010), A. aegypti (Bayyareddy et al. 2009). Vega-Cabrera also observed an interaction between Cry11Aa toxin and actin on the cytoplasmic side of the membrane after toxin penetration (Vega-Cabrera et al. 2014). In the present study, $\beta$-actin in $M$. persicae bound to the Cry1Ab1 toxic core. $\beta$-actin is involved in a wide range of cellular activities, including the transport of intracellular substances, cellular shape associated with cell movement, endocytosis, cytokinesis and cell adhesion (Brakebusch. and Fassler. 2003; Engqvist-Goldstein and Drubin. 2003; Suetsugu. and Takenawa. 2003; Ayscough. 2004). Notably, Cry toxins belong to the poreforming toxin family (PFT), which is the most widespread group of toxins produced by bacteria (Aroian and van der Goot. 2007). The interaction of PFT and actin not only enhances actin polymerization in vitro (Hupp et al. 2013) but indirectly promotes toxin oligomerization and endocytosis (Abrami et al. 2010). Therefore, we speculated that $\beta$-actin mediated the endocytosis of Cry1Ab1 located in cell membrane, and $\beta$-actin functioned as a cytoskeletal protein that binds to Cry1Ab1 and transports it to an intracellular site as the cytoplasm flows. $\beta$-actin is tightly integrated with RNA polymerase III (RNAP III) by interacting with RPABC3 (RPC62), RPABC2 (RPB6) and RPABC3 (RPB8) on RNAP III (Hu et al. 2004). Interestingly, RPABC2 and RPABC3, which are common subunits of RNAP $\otimes$, RNAP $₫$ and RNAP $₫$ (Schramm and

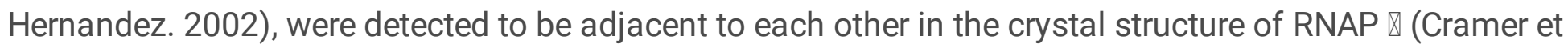
al. 2001), and $\beta$-actin has been shown to interact with RNAP $\triangle$ (Fomproix and Percipalle. 2004). Based on the analysis described above, we concluded that $\beta$-actin firmly binds to three RNAP by interacting with adjacent RPABC2, RPABC3 and other subunits, indicating that $\beta$-actin was quite important in the formation and function of RNAP. Once Cry1Ab1 bound to $\beta$-actin, it might hinder the normal assembly of RNAP, affecting the normal transcription and expression of genes, and then blocking the development and metabolism of M. persicae. Captivatingly, actin has also been reported to function as a receptor of beet western yellows virus particles in aphids, and probably played a role in the transcytosis and transmission of the virus (Seddas et al. 2004).Using a genomic analysis method, Tamborindeguy found that several actin proteins are potentially involved in the transcytosis of viruses in A. pisum (Tamborindeguy et al. 2010). Thus, after digestion by M. persicae, the binding of Cry1Ab1 to actin likely disturbs the interaction of actin and the virus, affecting virus transmission mediated by M. persicae. 
The GPN family, including Gpn1, Gpn2 and Gpn3, is known for its invariant glycine-proline-asparagine structural loop (Gras et al. 2007). Gpn2 is required for the proper localization of RNAPII and RNAPIII. As shown in the study by Zeng et al, Gpn2 might interact with RNA polymerases (Zeng et al. 2018), which have important roles in gene expression, cell fate determination and tissue development by catalyzing the synthesis of mRNA and non-coding RNA in eukaryotes (Sims et al. 2004; Kornberg. 2007; Liu et al. 2013). Zeng et al confirmed that Gpn2 and Rba50 are directly involved in the assembly of the Rpb3 subcomplex that bridges the Rpb1 and Rpb2 subcomplexes to produce the core of RNAPII, and even subsequent biogenesis of RNAPII (Zeng et al. 2018). Because $\beta$-actin might also bind tightly to RNAP and be involved in the formation and function of RNAP, the interaction of Cry1Ab1 with Gpn2 or $\beta$-actin would probably significantly disrupt the assembly and function of RNAP, as well as DNA transcription and expression, subsequently resulting in some damage to the metabolism and development of $M$. persicae.

From the above analysis, Cry1Ab1 toxic core interacted with Cry-binding protein including ATP synthase subunit alpha, $\beta$-actin and Gpn2, it would eventually affect the metabolism and development of $M$. persicae. Considering the pull down results and docking analysis, it is likely that Cry $1 \mathrm{Ab} 1$ toxic core bind with ATP synthase subunit alpha and $\beta$-actin or ATP synthase subunit alpha and Gpn2 to form protein complex, and the protein complex probably covered the functional domain of three Cry-binding proteins and dragged the ATP synthase subunit alpha, $\beta$-actin or Gpn2 to non-functional area of certain Crybinding protein, thereby potentially interrupting the normal energy supply, blocking the normal transcription and expression of genes and would eventually affect the metabolism and development of M. persicae.

Zhang et al identified Cry1 Ac/Ab in unfed Bt coccinellid Propylaea japonica neonates whose parents fed on aphids reared on Bt cotton (Zhang et al. 2006), suggesting that Cry $1 \mathrm{Ac} / \mathrm{Ab}$ enters the organelles and cell through parental transfer, and Cry1Ab1 protein was unable to be degraded and activated due to the neutral environment in the midgut of aphid (Rausch. 2014). This study proposed a hypothetical model for the molecular mechanism underlying the effect of Cry1Ab1 on aphids (Fig. 7). From the hypothetical model, Cry1Ab1 protein is unable to kill the aphid, but potentially affects development and reproduction. Some studies indicated an effect of Cry proteins on the growth and development of sucking insects. Paula and Andow found that Cry1 Ac and Cry1F toxin reduced the net population growth rate of $M$. persicae (Paula and Andow. 2016). Azimi et al reported a delay in the progression of Bemisia tabaci (Hemiptera) fed on Bt cotton expressing the Cry1 Ab protein to adulthood later and a lower level of fertility than insects fed on non-Bt cotton (Azimi. et al. 2016). Additionally, Porcar et al announced that after ingesting Cry $1 \mathrm{Ab}$, the growth rates of surviving $A$. pisum were markedly reduced compared to the control group (Porcar et al. 2009). Because the capsule method was a short-term bioassay that did not reflect the long-term effects of the Cry toxin on aphids, the Cry $1 \mathrm{Ab} 1$ toxic core rarely directly kills aphids, but it might affect the development of aphids and the reproduction of populations, similar to Cry $1 \mathrm{Ac}(86.17 \%$ of the amino acid sequence is the same as Cry1Ab1), which is less toxic to M. persicae but inhibits the population growth rate (Paula and Andow. 2016). The explanations for the inhibitory effects, however, remain unknown. Our study provided clues for the molecular mechanism of inhibition, namely, the proteins involved in cellular metabolic processes in M. persicae are bound by the Cry $1 \mathrm{Ab} 1$ toxic core. 
Based on the results reported by Pascale et al, actin is involved in the epithelial transcytosis of virus particles in the aphid vector (Seddas et al. 2004). This finding and the observation that actin is a common Cry-binding protein in our study and other studies prompted us to speculate that the Cry protein disrupt virus transmission mediated by aphids, providing a new strategy for controlling viral diseases mediated by aphids. Additionally, APN and translation elongation factor, which have been identified as other Cry-binding proteins in the aphid (unpublished data from our lab), were also proven to be involved in the interaction with the virus in aphids (Yamaji et al. 2006; Linz et al. 2015). APN is the receptor for numerous coronaviruses, such as porcine epidemic diarrhea virus (PEDV) and porcine transmissible gastroenteritis virus (TGEV) (Nam and Lee. 2010). Linz et al recently confirmed that the coat protein (CP) of pea enation mosaic virus (PEMV) binds to its receptor APN in the gut of the pea aphid (Linz et al. 2015). The interaction between elongation factor and viral RNA-dependent RNA polymerase (RdRp) or viral genomic RNA promotes virus replication and transmission (Yamaji et al. 2006). Thus, some aphid proteins are simultaneously bound by viral proteins and Cry proteins, further supporting our hypothesis that the Cry protein disrupts virus transmission mediated by aphids.

Last but not the least, based on the long-term feeding effect of Cry protein expressed in plant on aphid population, and the possibility that Cry protein disrupt virus transmission, when we screen anti-aphid Cry proteins, we should not only examine the short-term killing ability but also focus on the long-term effects on the growth and reproduction and virus transmission by aphids.

\section{Declarations}

\section{Author Contributions}

Liang Jin and Binwu Zhang contributed equally to this work. Binwu Zhang and Yi Lin conceived and designed the experiments; Liang Jin and Binwu Zhang conducted the experiments, analyzed the data, and wrote the manuscript; Xiaodi Zhao, Luis Carlos Ramos Aguila, and Yi Lin revised and approved the paper.

\section{Acknowledgments}

This study was supported by grants from the National Key Research and Development Program of China (Grant No. 2017YFD0201201), NNSFC (National Natural Science Foundation of China, Grant No. 31772227), and Fujian Key Laboratory of Ecology-toxicological Effects $\otimes$ Control for Emerging Contaminants (No. PY21002).

\section{Conflict of Interest Statement}

The authors declare that they have no competing interests.

\section{References}


1. Abrami L, Bischofberger M, Kunz B, Groux R, van der Goot FG (2010) Endocytosis of the anthrax toxin is mediated by clathrin, actin and unconventional adaptors. PLoS Pathog 6(3):e1000792. https://doi.org/10.1371/journal.ppat.1000792

2. Aroian R, van der Goot FG (2007) Pore-forming toxins and cellular non-immune defenses (CNIDs). Curr Opin Microbiol 10(1):57-61. https://doi.org/10.1016/j.mib.2006.12.008

3. Ayscough KR (2004) Endocytosis: Actin in the Driving Seat. Curr Biol 14(3):R124-R126. https://doi.org/10.1016/j.cub.2004.01.021

4. Azimi S, Rahmani. S, Tohidfar. M, Ashouri A (2016) Effect of Iranian Bt cotton on life table of Bemisia tabaci (Hemiptera: Alyrodidae) and Cry1Ab detection in the whitefly honeydew. Arthropods 5(3):8796

5. Ban L, Ahmed E, Ninkovic V, Delp G, Glinwood R (2008) Infection with an insect virus affects olfactory behaviour and interactions with host plant and natural enemies in an aphid. Entomol Exp Appl 127(2):108-117. https://doi.org/10.1111/j.1570-7458.2008.00675.x

6. Bayyareddy K, Andacht TM, Abdullah MA, Adang MJ (2009) Proteomic identification of Bacillus thuringiensis subsp. israelensis toxin Cry4Ba binding proteins in midgut membranes from Aedes (Stegomyia) aegypti Linnaeus (Diptera, Culicidae) larvae. Insect Biochem Mol Biol 39(4):279-286. https://doi.org/10.1016/j.ibmb.2009.01.002

7. Bourne HR, Sanders F (1990) The GTPase superfamily: a conserved switch for diverse cell functions. Nature 348(6297):125. https://doi.org/10.1038/348125a0

8. Fassler. BC R (2003) The integrin-actin connection, an eternal love affair. EMBO J 22(10):23242333. https://doi.org/10.1093/emboj/cdg245

9. Chen LZ, Liang GM, Zhang J, Wu KM, Guo YY, Rector BG (2010) Proteomic analysis of novel Cry1Ac binding proteins in Helicoverpa armigera (Hubner). Arch Insect Biochem Physiol 73(2):61-73. https://doi.org/10.1002/arch.20340

10. Chougule NP, Bonning BC (2012) Toxins for transgenic resistance to hemipteran pests. Toxins (Basel) 4(6):405-429. https://doi.org/10.3390/toxins4060405

11. Cramer P, Bushnell DA, Kornberg RD (2001) Structural basis of transcription: RNA polymerase II at 2.8 angstrom resolution. Science 292(5523):1863-1876. https://doi.org/10.1126/science.1059493

12. Cun $Y$, Frohlich $H$ (2013) Network and data integration for biomarker signature discovery via network smoothed T-statistics. PLoS ONE 8(9):e73074. https://doi.org/10.1371/journal.pone.0073074

13. Engqvist-Goldstein AE, Drubin DG (2003) Actin assembly and endocytosis: from yeast to mammals. Annu Rev Cell Dev Biol 19(1):287-332. https://doi.org/10.1146/annurev.cellbio.19.111401.093127

14. Faria CA, Wackers FL, Pritchard J, Barrett DA, Turlings TC (2007) High susceptibility of Bt maize to aphids enhances the performance of parasitoids of lepidopteran pests. PLoS ONE 2(7):e600. https://doi.org/10.1371/journal.pone.0000600

15. Farooq AV, Valyi-Nagy T, Shukla D (2010) Mediators and mechanisms of herpes simplex virus entry into ocular cells. Curr Eye Res 35(6):445-450. https://doi.org/10.3109/02713681003734841 
16. Miller. FC, GL, Nafria. JMN, Gabaudan FC (2007) Catalog of the Aphid Genera Described from the New World. T Am Entomol Soc 133(3):363-412. https://doi.org/10.3157/0002-8320-133.3.363

17. Feng B, Mandava CS, Guo Q, Wang J, Cao W, Li N, Zhang Y, Zhang Y, Wang Z, Wu J, Sanyal S, Lei J, Gao N (2014) Structural and functional insights into the mode of action of a universally conserved Obg GTPase. PLoS Biol 12(5):e1001866. https://doi.org/10.1371/journal.pbio.1001866

18. Feng M, He Z, Wang Y, Yan X, Zhang J, Hu Z, Wu W (2016) Isolation of the Binding Protein of Periplocoside E from BBMVs in Midgut of the Oriental Amyworm Mythimna separata Walker (Lepidoptera: Noctuidae) through Affinity Chromatography. Toxins (Basel) 8(5):139. https://doi.org/10.3390/toxins8050139

19. Fomproix N, Percipalle $P$ (2004) An actin-myosin complex on actively transcribing genes. Exp Cell Res 294(1):140-148. https://doi.org/10.1016/j.yexcr.2003.10.028

20. Forgac $M$ (1998) Structure, function and regulation of the vacuolar $(\mathrm{H}+)$-ATPases. Federation of European Biochemical Societies 440(3):258-263. https://doi.org/10.1016/S0014-5793(98)01425-2

21. Gras S, Chaumont V, Fernandez B, Carpentier P, Charrier-Savournin F, Schmitt S, Pineau C, Flament D, Hecker A, Forterre P, Armengaud J, Housset D (2007) Structural insights into a new homodimeric selfactivated GTPase family. EMBO Rep 8(6):569-675. https://doi.org/10.1038/sj.embor.7400958

22. Halbert. SE, Brown. GHCB, Niblett CL (2004) Distribution and Characterization of Citrus tristeza virus in South Florida Following Establishment of Toxoptera citricida. Plant Dis 88(9):935-941. https://doi.org/10.1094/PDIS.2004.88.9.935

23. Hu P, Wu S, Hernandez N (2004) A role for beta-actin in RNA polymerase III transcription. Genes Dev 18(24):3010-3015. https://doi.org/10.1101/gad.1250804

24. Hupp S, Fortsch C, Wippel C, Ma J, Mitchell TJ, Iliev Al (2013) Direct transmembrane interaction between actin and the pore-competent, cholesterol-dependent cytolysin pneumolysin. J Mol Biol 425(3):636-646. https://doi.org/10.1016/j.jmb.2012.11.034

25. Kang S, Odom OW, Thangamani S, Herrin DL (2017) Toward mosquito control with a green alga: Expression of Cry toxins of Bacillus thuringiensis subsp. israelensis (Bti) in the chloroplast of Chlamydomonas. J Appl Phycol 29(3):1377-1389. https://doi.org/10.1007/s10811-016-1008-z

26. Kornberg RD (2007) The molecular basis of eukaryotic transcription. P Natl Acad Sci USA 104(32):12955-12961. https://doi.org/10.1073/pnas.0704138104

27. Krishnamoorthy M, Jurat-Fuentes JL, McNall RJ, Andacht T, Adang MJ (2007) Identification of novel Cry1 Ac binding proteins in midgut membranes from Heliothis virescens using proteomic analyses. Insect Biochem Mol Biol 37(3):189-201. https://doi.org/10.1016/j.ibmb.2006.10.004

28. Linz LB, Liu S, Chougule NP, Bonning BC (2015) In Vitro Evidence Supports Membrane Alanyl Aminopeptidase N as a Receptor for a Plant Virus in the Pea Aphid Vector. J Virol 89(22):1120311212. https://doi.org/10.1128/JVI.01479-15

29. Liu X, Bushnell DA, Kornberg RD (2013) RNA polymerase II transcription: structure and mechanism. Biochim Biophys Acta 1829(1):2-8. https://doi.org/10.1016/j.bbagrm.2012.09.003 
30. Lu K, Gu Y, Liu X, Lin Y, Yu XQ (2017) Possible Insecticidal Mechanisms Mediated by ImmuneResponse-Related Cry-Binding Proteins in the Midgut Juice of Plutella xylostella and Spodoptera exigua. J Agric Food Chem 65(10):2048-2055. https://doi.org/10.1021/acs.jafc.6b05769

31. Nam E, Lee C (2010) Contribution of the porcine aminopeptidase N (CD13) receptor density to porcine epidemic diarrhea virus infection. Vet Microbiol 144(1):41-50. https://doi.org/10.1016/j.vetmic.2009.12.024

32. Nizet V (2010) Bacteria and phagocytes: mortal enemies. J Innate Immun 2(6):505-507. https://doi.org/10.1159/000320473

33. Palma L, Munoz D, Berry C, Murillo J, de Escudero IR, Caballero P (2014) Molecular and insecticidal characterization of a novel Cry-related protein from Bacillus thuringiensis toxic against Myzus persicae. Toxins (Basel) 6(11):3144-3156. https://doi.org/10.3390/toxins6113144

34. Park. Y, González-Martínez RM, Navarro-Cerrillo G, Chakroun M, Kim1. Y, Ziarsolo P, Blanca. J, Cañizares. FJ, Herrero (2014) S ABCC transporters mediate insect resistance to multiple Bt toxins revealed by bulk segregant analysis. BMC Biol 12(1):46. https://doi.org/10.1186/1741-7007-12-46

35. Paula DP, Andow DA (2016) Differential Cry toxin detection and effect on Brevicoryne brassicae and Myzus persicae feeding on artificial diet. Entomol Exp Appl 159(1):54-60. https://doi.org/10.1111/eea.12419

36. Peri F, Nüsslein-Volhard C (2008) Live imaging of neuronal degradation by microglia reveals a role for v0-ATPase a1 in phagosomal fusion in vivo. Cell 133(5):916-927. https://doi.org/10.1016/j.cell.2008.04.037

37. Pigott CR, Ellar DJ (2007) Role of receptors in Bacillus thuringiensis crystal toxin activity. Microbiol Mol Biol Rev 71(2):255-281. https://doi.org/10.1128/MMBR.00034-06

38. Porcar M, Grenier AM, Federici B, Rahbe Y (2009) Effects of Bacillus thuringiensis delta-endotoxins on the pea aphid (Acyrthosiphon pisum). Appl Environ Microbiol 75(14):4897-4900. https://doi.org/10.1128/AEM.00686-09

39. Rausch MA (2014) Modification of the Bt toxin Cry4Aa for improved toxin processing in the gut of the pea aphid (Acyrthosiphon pisum). Dissertations \& Theses Gradworks

40. Scholthof KB, Adkins S, Czosnek H, Palukaitis P, Jacquot E, Hohn T, Hohn B, Saunders K, Candresse T, Ahlquist P, Hemenway C, Foster GD (2011) Top 10 plant viruses in molecular plant pathology. Mol Plant Pathol 12(9):938-954. https://doi.org/10.1111/j.1364-3703.2011.00752.x

41. Schramm L, Hernandez N (2002) Recruitment of RNA polymerase III to its target promoters. Genes Dev 16(20):2593-2620. https://doi.org/10.1101/GAD.1018902

42. Seddas P, Boissinot S, Strub JM, Van Dorsselaer A, Van Regenmortel MH, Pattus F (2004) Rack-1, GAPDH3, and actin: proteins of Myzus persicae potentially involved in the transcytosis of beet western yellows virus particles in the aphid. Virology 325(2):399-412. https://doi.org/10.1016/j.virol.2004.05.014

43. Shan LT, Feng MG (2010) Evaluation of the biocontrol potential of various Metarhizium isolates against green peach aphid Myzus persicae (Homoptera: Aphididae). Pest Manag Sci 66(6):669-675. 
https://doi.org/10.1002/ps.1928

44. Sims RJ, Mandal III, Reinberg SS D (2004) Recent highlights of RNA-polymerase-Il-mediated transcription. Curr Opin Cell Biol 16(3):263-271. https://doi.org/10.1016/j.ceb.2004.04.004

45. Sprang SR (1997) G PROTEIN MECHANISMS: Insights from Structural Analysis. Annu Rev Biochem 66639-66678. https://doi.org/10.1146/annurev.biochem.66.1.639

46. Stenfors Arnesen LP, Fagerlund A, Granum PE (2008) From soil to gut: Bacillus cereus and its food poisoning toxins. FEMS Microbiol Rev 32(4):579-606. https://doi.org/10.1111/j.1574-

6976.2008.00112.x

47. Stuart LM, Ezekowitz RA (2008) Phagocytosis and comparative innate immunity: learning on the fly. Nat Rev Immunol 8(2):131-141. https://doi.org/10.1038/nri2240

48. Suetsugu S, Takenawa. T (2003) Regulation of Cortical Actin Networks in Cell Migration. Int Rev Cytol 229245-229286. https://doi.org/10.1016/S0074-7696(03)29006-9

49. Tamborindeguy C, Monsion B, Brault V, Hunnicutt L, Ju HJ, Nakabachi A, Van Fleet E (2010) A genomic analysis of transcytosis in the pea aphid, Acyrthosiphon pisum, a mechanism involved in virus transmission. Insect Mol Biol. https://doi.org/10.1111/j.1365-2583.2009.00956.x. 19 Suppl $2259-272$

50. Tanji T, Ip YT (2005) Regulators of the Toll and Imd pathways in the Drosophila innate immune response. Trends Immunol 26(4):193-198. https://doi.org/10.1016/j.it.2005.02.006

51. Toei M, Saum R, Forgac M (2010) Regulation and isoform function of the V-ATPases. Biochemistry 49(23):4715-4723. https://doi.org/10.1021/bi100397s

52. Torres-Quintero MC, Arenas-Sosa I, Zuniga-Navarrete F, Hernandez-Velazquez VM, Alvear-Garcia A, Pena-Chora G (2022) Characterization of insecticidal Cry1Cb2 protein from Bacillus thuringiensis toxic to Myzus persicae (Sulzer). J Invertebr Pathol 189107731.

https://doi.org/10.1016/j.jip.2022.107731

53. Vega-Cabrera A, Cancino-Rodezno A, Porta H, Pardo-Lopez L (2014) Aedes aegypti Mos20 cells internalizes cry toxins by endocytosis, and actin has a role in the defense against Cry11Aa toxin. Toxins (Basel) 6(2):464-487. https://doi.org/10.3390/toxins6020464

54. Whyard S, Singh AD, Wong S (2009) Ingested double-stranded RNAs can act as species-specific insecticides. Insect Biochem Mol Biol 39(11):824-832. https://doi.org/10.1016/j.ibmb.2009.09.007

55. Wilson DF (2017) Oxidative phosphorylation: regulation and role in cellular and tissue metabolism. J Physiol 595(23):7023-7038. https://doi.org/10.1113/JP273839

56. Yamaji Y, Kobayashi T, Hamada K, Sakurai K, Yoshii A, Suzuki M, Namba S, Hibi T (2006) In vivo interaction between Tobacco mosaic virus RNA-dependent RNA polymerase and host translation elongation factor 1A. Virology 347(1):100-108. https://doi.org/10.1016/j.virol.2005.11.031

57. Yusuf SW, Collins GG (1998) Effect of soil sulphur levels on feeding preference of Brevicoryne brassicae on brussels sprouts. J Chem Ecol 24(3):417-424.

https://doi.org/10.1023/A:1022308417053

Page 14/21 
58. Zeng F, Hua Y, Liu X, Liu S, Lao K, Zhang Z, Kong D (2018) Gpn2 and Rba50 Directly Participate in the Assembly of the Rpb3 Subcomplex in the Biogenesis of RNA Polymerase II. Mol Cell Biol 38(13):e00091-e00018. https://doi.org/10.1128/MCB.00091-18

59. Zhang G-f, Wan F-h, Lövei GL, Liu W-x, Guo J-y (2006) Transmission of Bt Toxin to the Predator Propylaea japonica (Coleoptera: Coccinellidae) Through Its Aphid Prey Feeding on Transgenic Bt Cotton. Environ Entomol 35(1):143-150. https://doi.org/10.1111/j.1570-7458.2006.00386.x

60. Zhang L, Hu X, Wu S, Batool K, Chowdhury M, Lin Y, Zhang J, Gill SS, Guan X, Yu X (2018) Aedes aegypti Galectin Competes with Cry11Aa for Binding to ALP1 To Modulate Cry Toxicity. J Agric Food Chem 66(51):13435-13443. https://doi.org/10.1021/acs.jafc.8b04665

61. Zhao X, Zhang B, Fu L, Li Q, Lin Y, Yu X (2020) Possible Insecticidal Mechanism of Cry41-Related Toxin against Myzus persicae by Enhancing Cathepsin B Activity. J Agric Food Chem 68(16):46074615. https://doi.org/10.1021/acs.jafc.0c01020

\section{Figures}

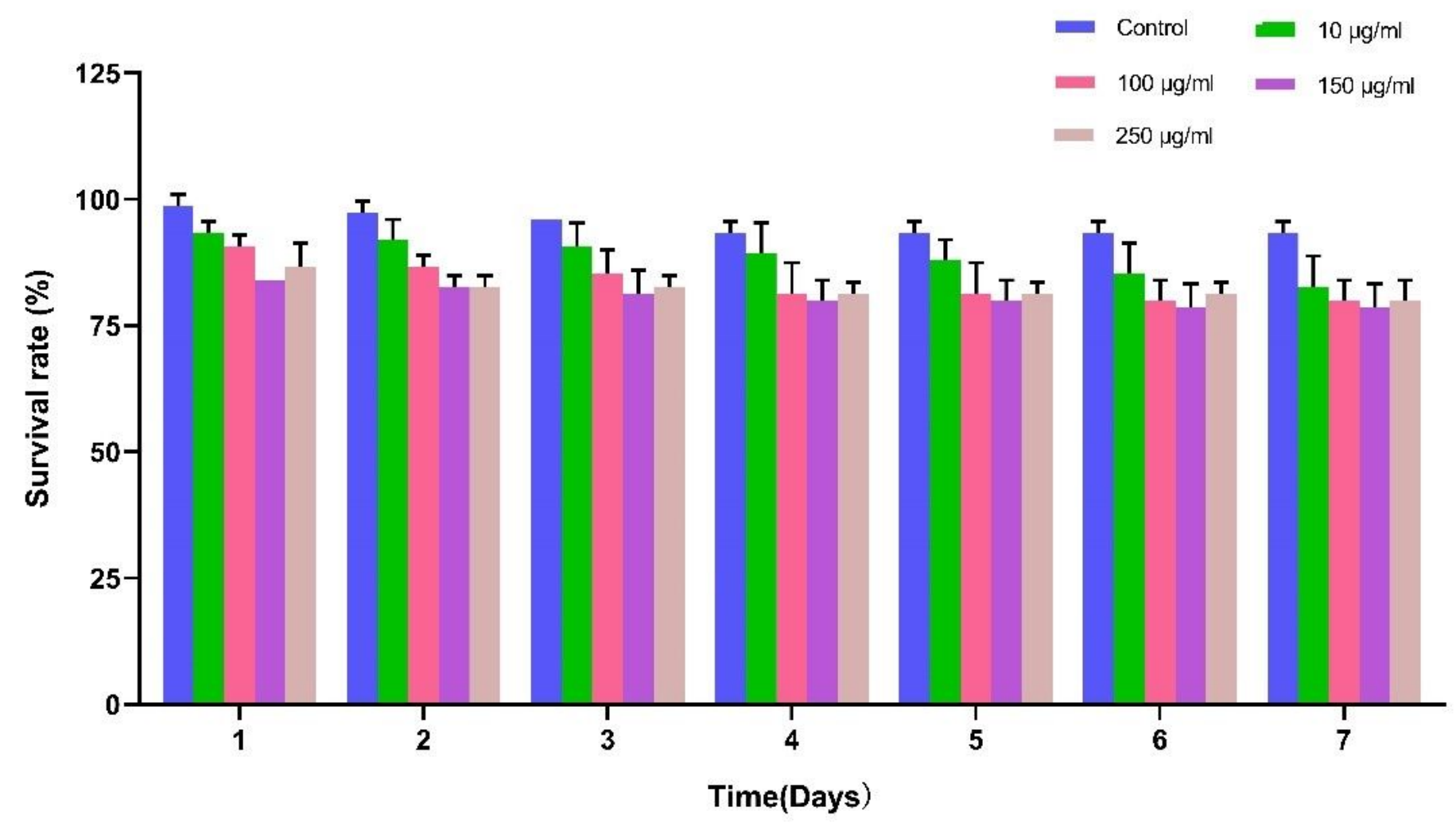

Figure 1

The ability of the Cry1Ab1 toxic core to kill M. persicae.

The concentration of Cry1Ab1 toxic core was administered at concentrations of 10, 100, 150, and 250 $\mu \mathrm{g} / \mathrm{ml}$ to the four experimental groups in the bioassay for 1-7 days; the concentration of $0 \mu \mathrm{g} / \mathrm{ml}$ served as the control. 


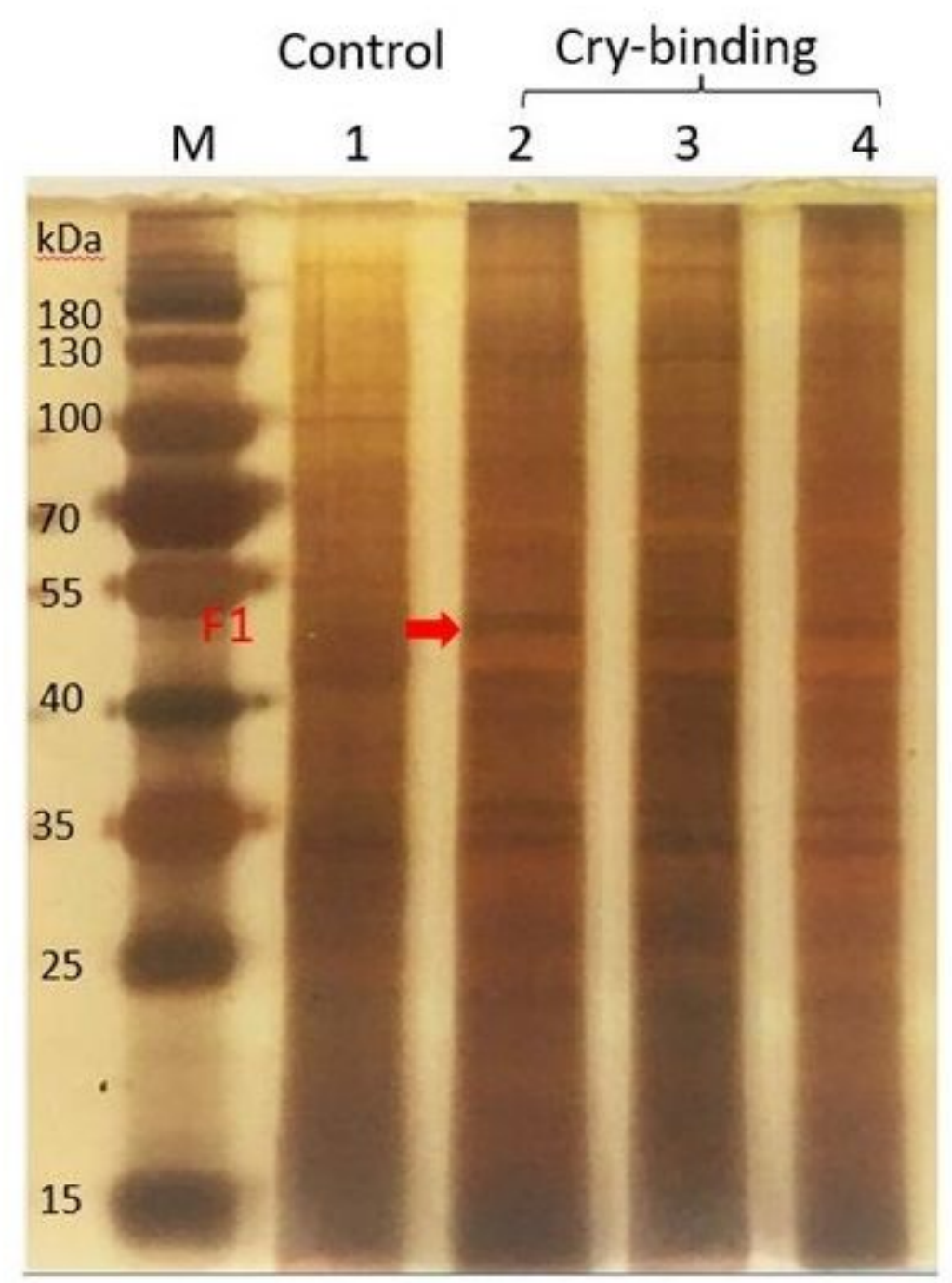

Figure 2

Isolation of $\mathrm{Cry} 1 \mathrm{Ab} 1$ toxic core-binding proteins in M. persicae.

M: Protein Marker $(180,130,100,70,55,40,35,25$, and $15 \mathrm{kDa})$; Control: $\mathrm{CNBr}^{\mathrm{TM}}$-activated Sepharose 4B + aphid homogenate; Cry-binding: Cry1 $\mathrm{Ab} 1$ toxic core+ $\mathrm{CNBr}^{\mathrm{TM}}$-activated Sepharose $4 \mathrm{~B}+$ aphid homogenate. 


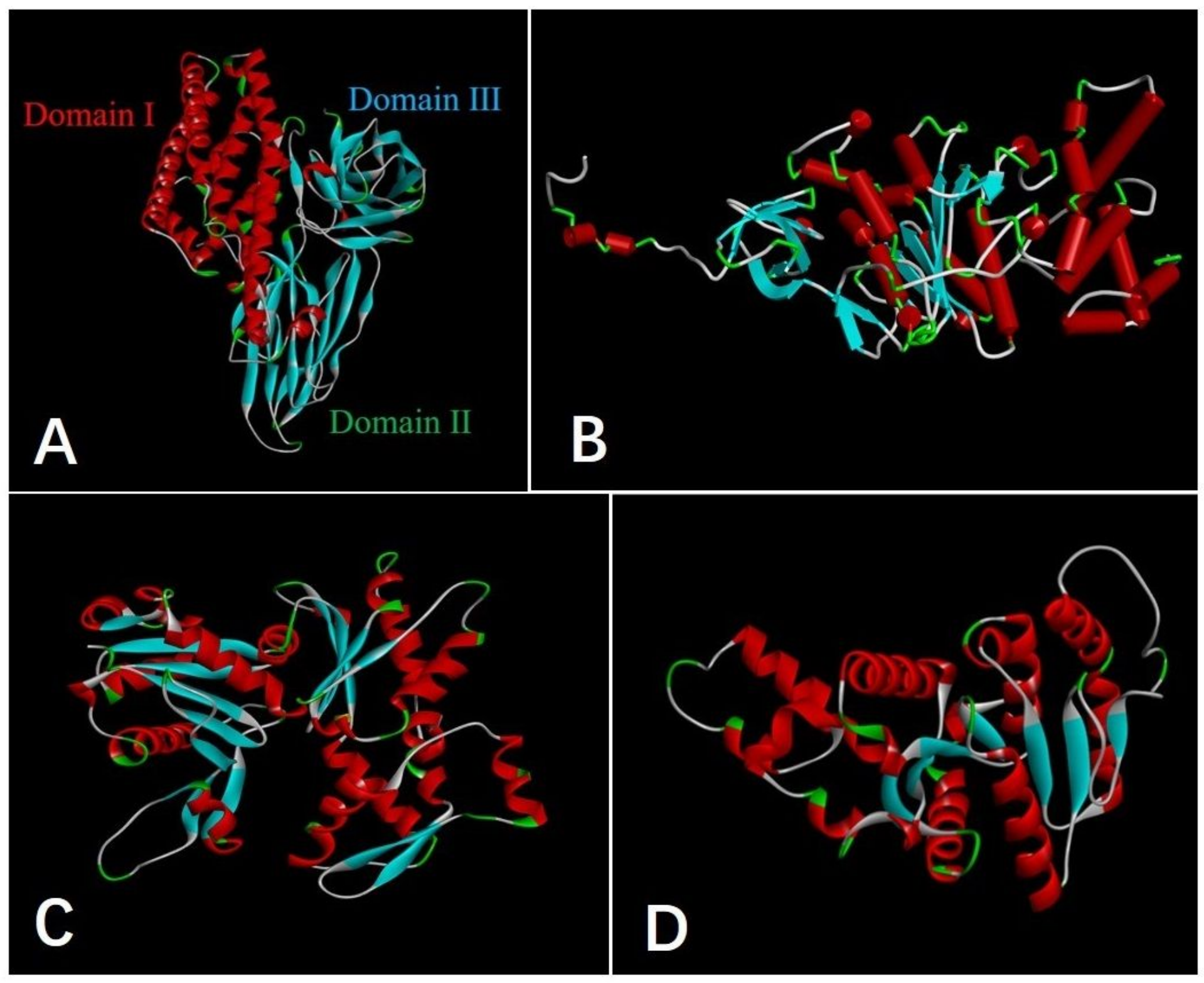

Figure 3

3D structure of Cry1Ab1 toxic core and its binding proteins.

A: Cry1Ab1 toxic core; B: ATP synthase subunit alpha; C: $\beta$-actin; D: GPN-loop GTPase 2. 


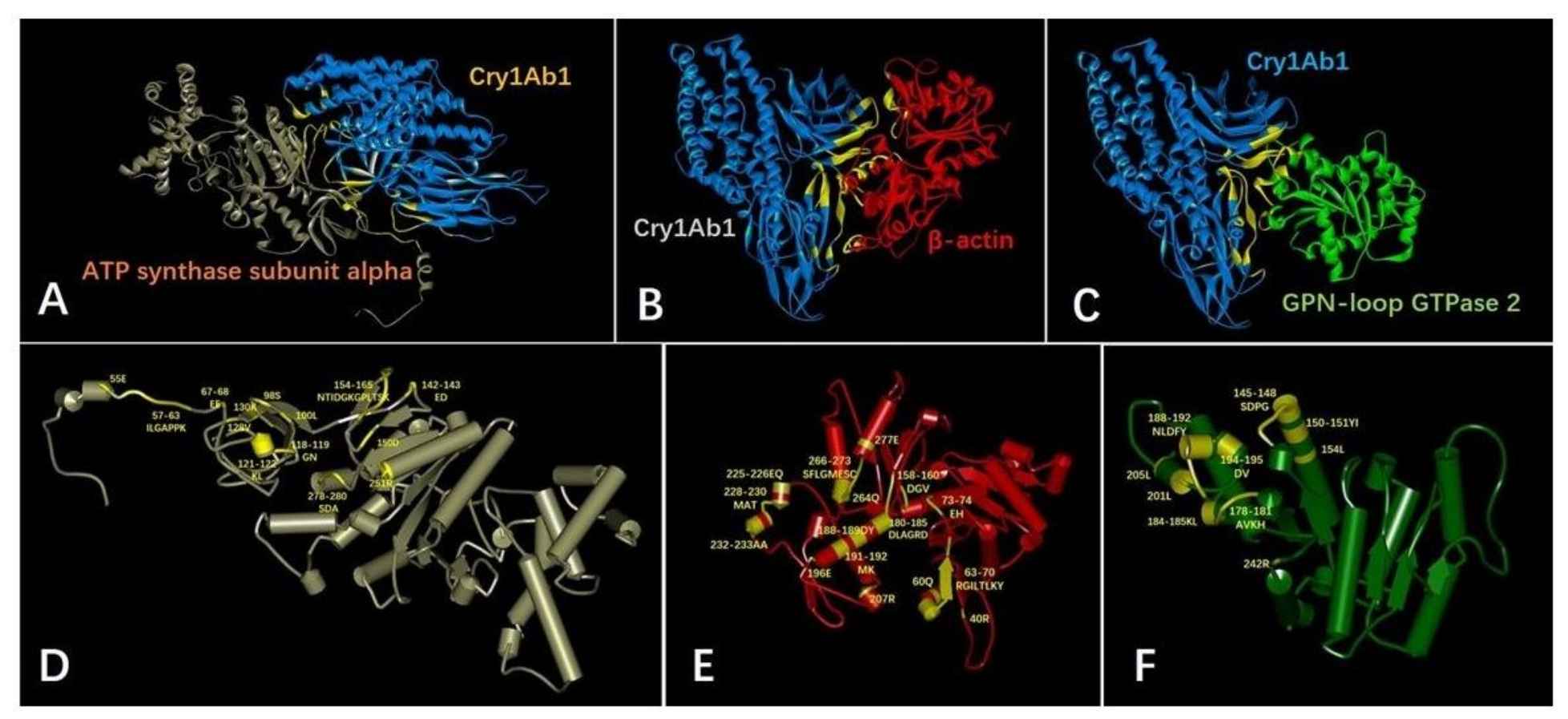

\section{Figure 4}

\section{Interface between $\mathrm{Cry} 1 \mathrm{Ab} 1$ and its binding proteins}

A: Molecular docking between Cry1Ab1 toxic core and ATP synthase subunit alpha, Cry1Ab1 toxic core (blue), ATP synthase subunit alpha (gray), docking interface (yellow); B: Molecular docking between Cry1Ab1 toxic core and $\beta$-actin, Cry1Ab1 toxic core (blue), $\beta$-actin (red), docking part (yellow); C: Molecular docking between Cry1Ab1 toxic core and GPN-loop GTPase 2, Cry1Ab1 toxic core (blue), GPN-loop GTPase 2 (green), docking part (yellow); D: Interacting residues between Cry1Ab1 toxic core and ATP synthase subunit alpha (showed on ATP synthase subunit alpha); E: Interacting residues between Cry1Ab1 toxic core and $\beta$-actin (showed on $\beta$-actin); F: Interacting residues between Cry1Ab1 toxic core and GPN-loop GTPase 2 (showed on GPN-loop GTPase 2). 


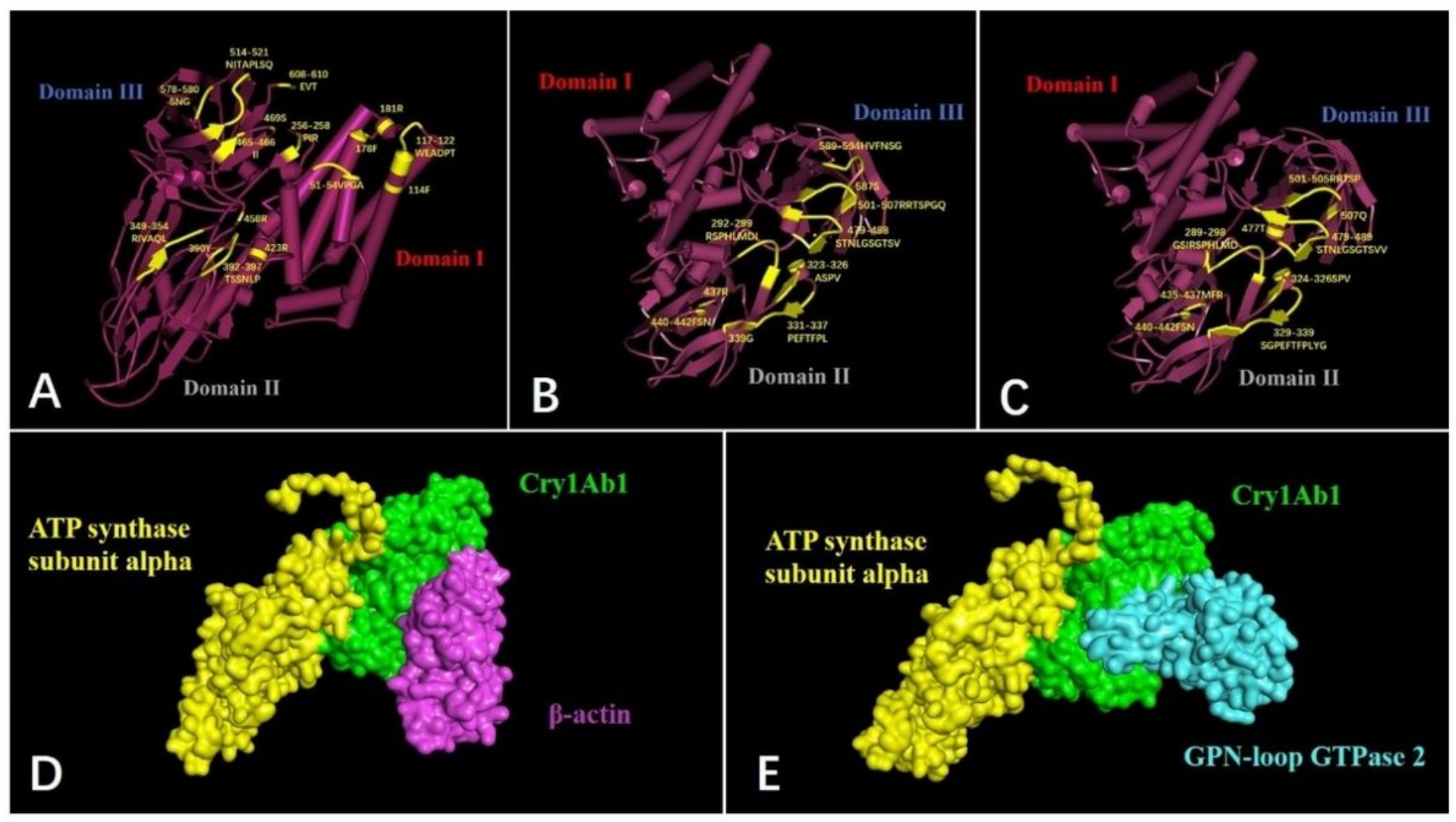

\section{Figure 5}

The locations on Cry1Ab1 where the three proteins bind and the two complexes

A: Interacting residues between Cry1Ab1 toxic core and ATP synthase subunit alpha (showed on Cry1Ab1 toxic core); B: Interacting residues between Cry1Ab1 toxic core and $\beta$-actin (showed on Cry1Ab1 toxic core); C: Interacting residues between Cry1Ab1 toxic core and GPN-loop GTPase 2 (showed on Cry1Ab1 toxic core); D: Protein complex composed of Cry1Ab1 toxic core (green), ATP synthase subunit alpha (yellow) and $\beta$-actin (purple); E: Protein complex composed of Cry1Ab1 toxic core (green), ATP synthase subunit alpha (yellow) and GPN-loop GTPase 2 (blue). 


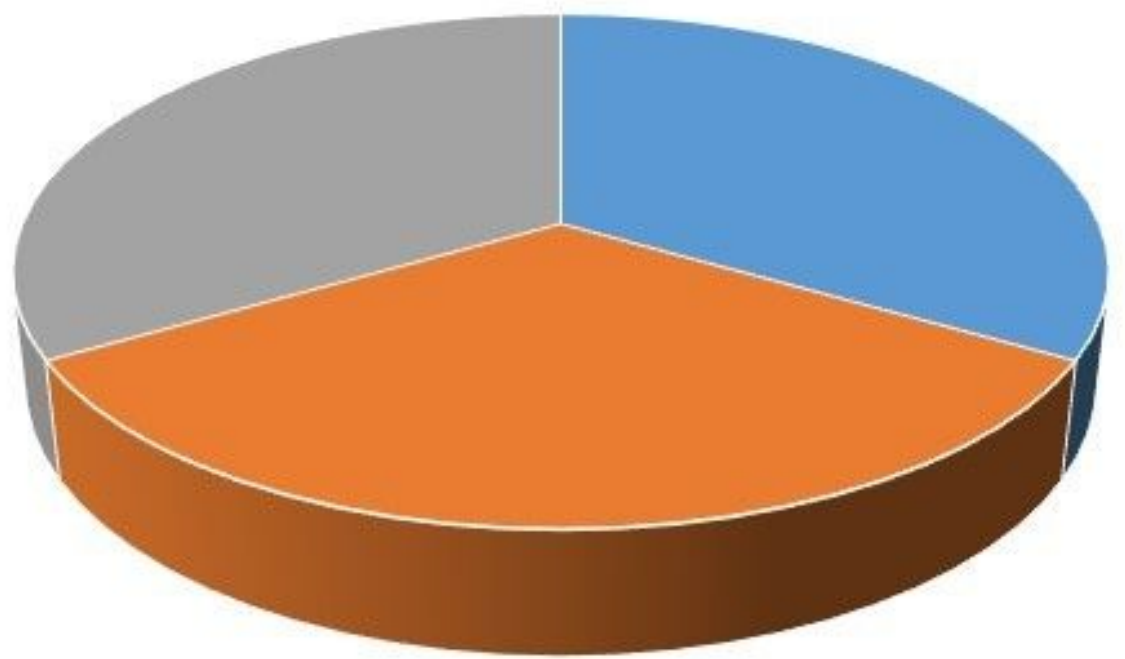

- phagosome = RNA polymerase - oxidative phosphorylation

Figure 6

Predicted network for the Cry1Ab1 toxic core-binding proteins. 


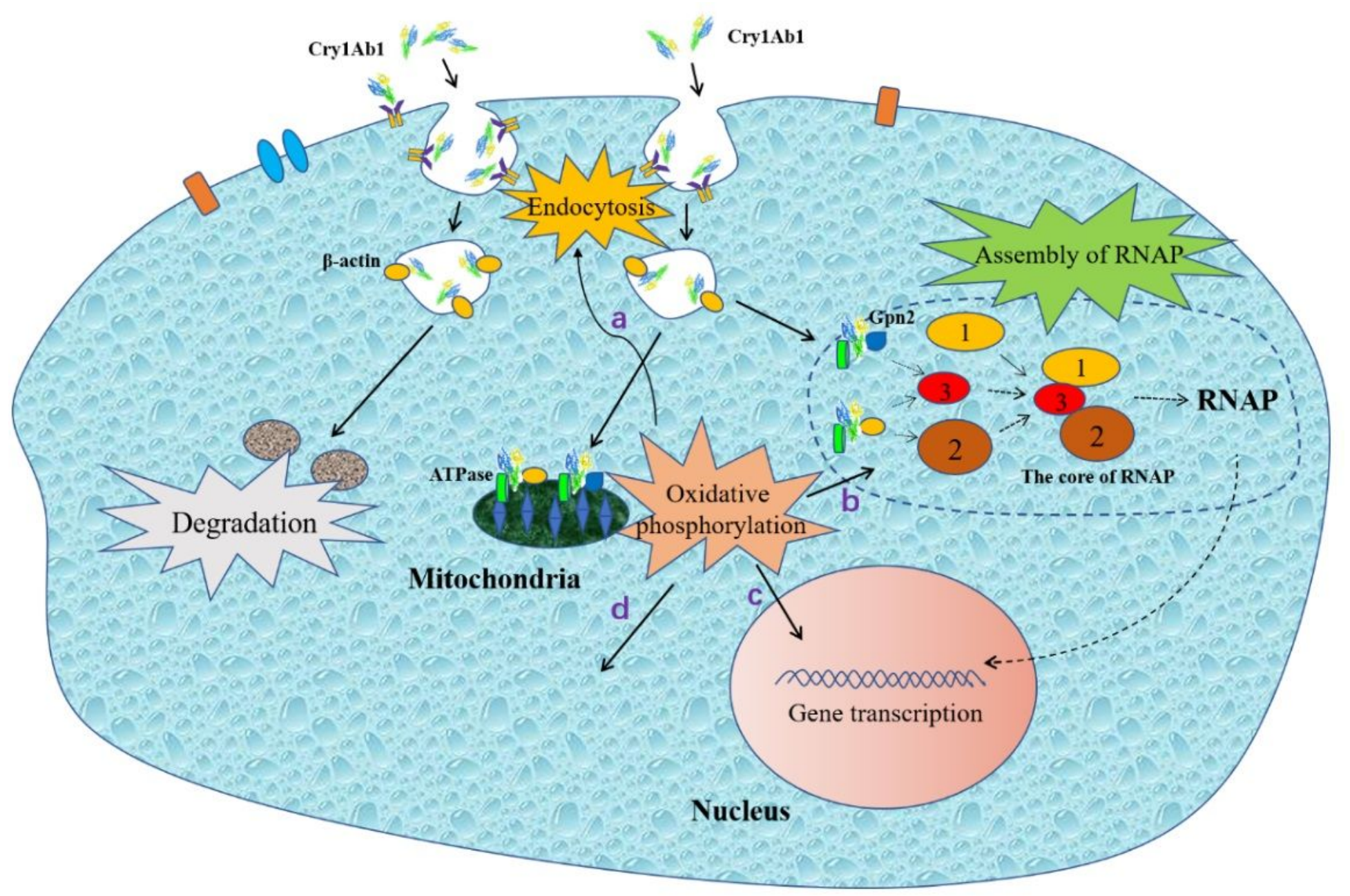

Figure 7

\section{A model for the molecular mechanism of Cry1Ab1 in aphid cell.}

After ingestion by the aphid, Cry1Ab1 entered aphid cells by clathrindriven endocytosis and interacts with $\beta$-actin. Subsequently, most of the Cry1Ab1 is transported to be degraded, whereas the remaining protein is transported to various organelles to participate in the two processes described below. First, some Cry1Ab1 is transported to the mitochondria and then binds to ATP synthase subunit alpha of ATPase, with interacting with $\beta$-actin or Gpn2 simultaneously, disrupting oxidative phosphorylation and affecting paths a) the ATP required for endocytosis; $b$ ) the ATP required for the assembly of RNAP; $c$ ) the ATP required for gene transcription; and d) the ATP required for other reactions. Second, Cry1Ab1 disrupts the assembly of RNAP. Briefly, the protein complex consisting of Cry1Ab1, ATPase and $\beta$-actin prevents $\beta$ actin from binding to subcomplex 2 and subcomplex 3 . Additionally, the protein complex consisting of Cry1Ab1, ATPase and Gpn2 disrupts the normal interaction of Gpn2 with subcomplex 3, affecting the assembly of the core and entire complex of RNAP to subsequently disrupt gene transcription in the nucleus. (Dotted arrow represents the processes that are unable to be performed normally because they are disrupted) 